\title{
Tecnologia e "Morte Natural": o Morrer na Contemporaneidade
}

\author{
RACHELAISENGART MENEZES
}

\section{RESUMO}

O desenvolvimento de técnicas voltadas ao prolongamento da vida acarretou mudanças significativas na concepção de morte. Este artigo analisa as representações contemporâneas da "morte natural" e sua relação com o uso de tecnologias médicas. Através de revisão bibliográfica, são examinadas as concepções de "morte natural" e de "morrer bem" construídas pelos diversos atores sociais envolvidos no processo do morrer. A literatura evidencia a construção contemporânea de um ideário e de uma trajetória necessários à realização do modelo da "boa morte". Esse modelo do "morrer bem" é construído em contraposição ao uso de técnicas para o prolongamento da vida. Estudos apontam a complexidade e ambivalência presentes no que seriam a morte natural ou não-natural, pois essas representações se encontram imbricadas com a concepção da "boa morte" como escolhida e produzida pelo doente. Deste modo, a tecnologia médica torna-se intrinsecamente constitutiva do "morrer natural".

Palavras-chave: Morte; tecnologia médica; morte natural; cuidados paliativos. 
Pensar o corpo é outra maneira de pensar o mundo e o vínculo social; uma perturbação introduzida na configuração do corpo é uma perturbação introduzida na coerência do mundo.

David Le Breton (1995, p. 65).

\section{Introdução}

Este artigo versa sobre as concepções construídas pelos diversos atores sociais envolvidos no processo do morrer, sobre a "morte natural" e a "boa morte" e suas relações com a utilização de tecnologia médica. Na revisão bibliográfica realizada sobre o uso de recursos tecnológicos para a manutenção da vida, surge o processo de medicalização do social como referência central nas diversas representações do morrer na contemporaneidade. A produção analítica e crítica considera que a medicalização pode ser entendida como o processo pelo qual a evolução tecnológica continuada vem modificando as práticas da medicina, por meio de inovações em várias áreas, tais como: métodos diagnósticos e terapêuticos, indústria farmacêutica e equipamentos médicos.

O desenvolvimento de novas tecnologias teria como corolário um aumento no consumo de atos médicos e de medicamentos. A medicalização do social pode ser referida à redescrição médica de eventos como gravidez, parto, menopausa, envelhecimento, e de comportamentos sociais tidos como desviantes. Em suma, a medicalização tanto pode ser compreendida como a ampliação de atos, produtos e consumo médico como a interferência crescente da medicina no cotidiano individual, através da imposição de normas de conduta social (Corrêa, 2001, p. 24). Pensar a medicalização implica necessariamente considerar a interferência da prática e do discurso médicos na construção dos sentidos e significados das idéias de vida e de processos vitais, tais como saúde, doença e morte.

Na sociedade ocidental contemporânea, o processo de medicalização é basicamente ancorado no corpo e este é o vetor da individualização, ao estabelecer a fronteira da identidade pessoal. Deste modo, os processos de individualização e de medicalização encontram-se intrinsecamente articulados: examinar as formas de apropriação e consumo das tecnologias médicas nas diversas etapas da vida e em relação aos comportamentos humanos implica investigar as configurações de corpo e pessoa construídas social- 
mente. Atualmente há extensa produção analítica acerca dos processos de medicalização das diversas etapas da vida, como os métodos de fertilização artificial, acompanhamento e interferência na gestação, parto, envelhecimento e morte. Pensar cada um desses processos seria como visualizar uma das faces do prisma. Neste artigo nos atemos apenas a um aspecto de uma das possíveis faces do prisma.

O processo de medicalização social teria se iniciado no século XIX, com extenso e profundo desenvolvimento ao longo do século XX, quando surgiram inúmeras tecnologias aplicadas à medicina (Foucault, 1999, p. 111). Ao longo do século $\mathrm{XX}$, foram criados vários recursos voltados à manutenção da vida, tais como pulmão de aço, respiradores artificiais, desfibriladores, monitores de funções corporais, aparelhos de diálise, entre outros. A estrutura institucional e a arquitetura hospitalar - que vinham se transformando e se modificando desde o século XIX - foram reorganizadas, com a criação de setores e serviços específicos, como as Unidades de Tratamento Intensivo, as UTIs Neonatais, os Centros de Tratamento de Queimados, onde se encontram aparelhagem moderna e sofisticada e equipes altamente especializadas.

Através do emprego de tecnologia médica para a manutenção da vida, com a criação e utilização do ventilador artificial, ocorreram profundas alterações tanto no processo do morrer quanto no próprio conceito de morte. É construído o diagnóstico de morte cerebral, articulado ao transplante de órgãos (Lock, 2000, p. 233). A morte de distintas partes do corpo, de que falava Bichat, tornou-se uma morte sucessiva do mesmo indivíduo através da tecnologia médica (Le Breton, 1995, p. 62). Assim, a imagem temida da morte foi transformada: o tradicional esqueleto com a foice foi substituído, no século XX, pela imagem de um internado em CTI, só, invadido por tubos e cercado de aparelhos. Esse modelo de morte, denominado "morte moderna" por diversos autores, tornou-se objeto de análises críticas a partir dos anos 1960, especialmente no âmbito das ciências sociais ${ }^{2}$.

Nas produções iniciais e nas que se seguiram, emergiam, como problemáticas centrais, o processo de despersonalização dos internados em hospitais, o crescente poder do médico e a conseqüente desumanização, assujeitamento ou objetificação do enfermo, em especial do moribundo. A "morte moderna" é definida como um processo eminentemente medicalizado, no qual o doente terminal é submetido a regras e rotinas institucionais que privilegiam a competência e a eficácia médicas. Nesse modelo, o moribundo se encontra entregue às mãos do médico, com poucas possibilidades de 
acesso ao conhecimento do que se passa consigo e às possíveis opções terapêuticas.

\section{A "Morte Contemporânea": a construção da "boa morte"}

A partir do final da década de 60 do século XX, em contraposição à crescente expansão do poder médico e à medicalização social, surgiram diversos movimentos de defesa dos direitos dos doentes e de humanização na prática dos cuidados aos doentes. As reivindicações abrangeram desde o direito a "morrer com dignidade" até a regulamentação da eutanásia. Nesse contexto emergiu um discurso propondo novas práticas em relação à morte advinda de doença crônica terminal, no qual a relação de poder entre paciente e equipe profissional seria transformada. Esse novo modelo foi chamado de "morte contemporânea", "neomoderna" ou "pós-moderna"3.

O desenvolvimento de pesquisas voltadas ao controle da dor de doentes terminais foi fator relevante na aplicação prática do ideário da "morte contemporânea". A Inglaterra e os Estados Unidos foram os primeiros países a implantar o novo modelo. Os movimentos de protesto contra o abandono dos moribundos pelo sistema de saúde inglês foram se expandindo e, em 1985, foi fundada a Associação de Medicina Paliativa da Grã-Bretanha e Irlanda. Nos Estados Unidos, o movimento inicial pelos cuidados paliativos foi principalmente "antimédico"4

Enquanto no modelo da "morte moderna", "a morte é, tanto para o médico como para o hospital, antes de tudo, um fracasso" (Herzlich, 1993, p. 7), no modelo contemporâneo da "boa morte", a equipe de saúde compreende a morte de modo distinto - e, conseqüentemente, busca posicionarse de nova forma. A proposta dos profissionais consiste em assistir o moribundo até seus últimos momentos, buscando minimizar, tanto quanto possível, sua dor e desconforto, e dar suporte emocional e espiritual a seus familiares. Na filosofia da "morte contemporânea", o ideal é que o indivíduo que está a morrer tenha controle do processo de morte, realizando escolhas a partir das informações sobre as técnicas médicas e espirituais que considerar adequadas, diversamente do que ocorria no modelo da "morte moderna", quando o doente era destituído tanto do conhecimento de sua situação como de suas possibilidades de opção. Os sentimentos e preferências do "morredor" teriam precedência sobre os regimes estandardizados das equipes de saúde. O morrer na própria residência é estimulado, se for o desejo do paciente e de sua família. Os familiares do doente passam a ser consi- 
derados pelos profissionais de saúde como membros da equipe de cuidados paliativos - postura bastante distinta do que ocorria no modelo da "morte moderna", quando eram percebidos como atores sociais que causavam interferências negativas no tratamento ${ }^{5}$.

O modelo da "morte contemporânea" é construído visando a uma "boa morte", definida por seus divulgadores como a "escolhida" e "produzida" pelo indivíduo que está a morrer, e compreende as categorias de autonomia do doente e dignidade no morrer. Inserido nesse modelo da "morte contemporânea", surge, na Inglaterra, nos anos 1990, o movimento pela "morte natural", inspirado no modelo do parto natural e da "humanização do parto" $"$.

\section{A "Boa Morte" e a "Morte Natural"}

Em 1991 foi fundado na Inglaterra o Natural Death Center, instituição educacional sem fins lucrativos, visando a divulgar o ideário da "morte natural". O Centro publicou em 1993 um manual da "morte natural" (Albery e Wienrich, 2000), sucesso de vendas na Inglaterra.

O manual veicula casos paradigmáticos do "morrer bem" e da prática do luto "saudável", apresentando uma argumentação em prol do morrer "o mais naturalmente" possível, a exemplo do movimento pelo parto "natural" e humanizado. Propõe-se a ensinar as melhores formas de cuidar de doentes terminais. Os autores argumentam que, se há uma preparação para o parto, através de exercícios corporais, visando a propiciar a redução da ansiedade da parturiente e que o bebê possa "nascer sorrindo", da mesma forma, com relação ao morrer, poderiam ser desenvolvidas práticas voltadas a uma redução da ansiedade diante da morte. Indo além, os autores propõem que, à semelhança do parto, que pode ser vivido como um processo de êxtase por muitas mulheres, o morrer poderia ser vivido do mesmo modo. Os autores do manual reivindicam amplas mudanças sociais diante do morrer, tanto nas políticas públicas de assistência aos doentes terminais, como na área da educação, voltada a profissionais de saúde, à população em geral e, em especial, à infância. O objetivo do projeto é tornar a morte socialmente mais visível, de modo a ser concebida e vivida "naturalmente", como um evento que faz parte do ciclo da vida. Os militantes do movimento pela "morte natural" elaboram críticas ao culto atualmente desenvolvido à juventude, à medicalização da sociedade e à fragmentação dos vínculos sociais.

Para Albery e Wienrich, a necessidade de construção de um modelo de 
"morte natural" teria surgido em decorrência do envelhecimento da geração dos anos $1960^{7}$. Uma das metas da velhice e do envelhecimento seria a construção de uma "boa morte natural". Os divulgadores do ideário da "morte natural" consideram que a própria morte - ou o acompanhamento do morrer de alguém próximo - seria uma etapa de desenvolvimento pessoal.

Para atingir seus objetivos, o movimento organiza palestras voltadas à divulgação de seus ideais, bem como cursos para educação e debate das novas formas de vivência e cuidados diante da morte. O Centro propõe-se a discutir questões em torno do final da vida, tais como a recusa de alimentação por parte de doentes terminais, as experiências de quase-morte e seus significados e a importância da construção do morrer individualizado e singularizado - "ao seu próprio jeito".

Os militantes da causa da "morte natural" apresentam propostas práticas, dentre as quais a manutenção de leito compartilhado pelo moribundo com pessoa de sua relação (como esposo/a), a exemplo do leito compartilhado no caso de parto natural, e a prática de técnicas para possibilitar melhor vivência da morte, se não como um êxtase, ao menos com aceitação e de modo mais relaxado. Essas técnicas incluem massagens corporais, escuta de fitas com músicas especialmente confeccionadas para relaxamento, uso de florais de Bach, exercícios respiratórios e de visualização e elaboração de mensagens, como "vá para a luz, vá ao encontro da luz", que seriam sussurradas aos moribundos.

As propostas do movimento não excluem as intervenções médicas (uso de medicações analgésicas, radioterapia, antidepressivos, anticonvulsivantes, ultra-som, bloqueios nervosos), desde que sob o controle do paciente, considerando que este possa decidir suspendê-las no final da vida (Albery, 2000, p. 91). Segundo os autores do manual, no passado muitos médicos e enfermeiras percebiam a morte como uma falha de suas habilidades, afastandose do moribundo, pois ele apontava as limitações dos profissionais em manter a vida.

De acordo com os divulgadores do ideário, surge na contemporaneidade - em contraposição à crescente tecnologização social - a necessidade de um retorno pagão à natureza: os doentes terminais devem permanecer ao ar livre, em sítios, se possível junto a um rio ou cachoeira, cercados de animais domésticos, o mais próximo possível da natureza. Os militantes postulam que, em caso de internação hospitalar, a instituição permita que os doentes recebam flores e animais de estimação.

O projeto da "morte natural" é amplo e abrangente, chegando a postular 
a profissionalização das "parteiras para o moribundo" e a confecção de um livro inglês dos mortos, que traduziria as compreensões tibetanas sobre a experiência e a psicologia do morrer, com relatos dos que viveram experiências de quase-morte em uma visão anglo-saxônica. Para que a meta da "boa morte" seja alcançada, a equipe médica deve reconhecer seus limites e saber que uma morte pacífica pode ser uma das metas de seu trabalho e, assim, os profissionais de saúde deveriam ter permissão para pesquisar e utilizar drogas e agentes psicoativos, com o objetivo de ajudar os moribundos a alcançar uma percepção melhor e mais ampla de sua situação. Em suma, os autores do manual enfatizam a naturalidade da morte e a busca contemporânea de uma nova construção filosófica da morte, acarretando novas posturas e práticas em torno do processo do morrer.

\section{A "Morte Natural" e a Medicalização}

O ideário da "morte natural", tal como apresentado por seus militantes, é radicalmente antitecnológico: a tecnologia é tida como antagonista da "boa morte", com dignidade. Aparentemente, a proposta da "morte natural" é de suspensão do uso de tecnologia, e sua retórica é construída de modo a não enfocar dois relevantes aspectos sobre a morte e uso de tecnologia na contemporaneidade. $\mathrm{O}$ primeiro seria relativo aos significados atribuídos à tecnologia, uma vez que a tecnologia não possui um sentido em si, fechado, sendo este dado pelas interpretações e representações construídas nos distintos contextos históricos, culturais e sociais. Deste modo, o projeto da "morte natural" exalta e enfatiza a utilização de recursos tidos como "naturais", advindos de práticas orientais, como respiração, meditação, massagem e visualização, sem levar em conta que estes não deixam de ser recursos técnicos.

Com relação ao processo do morrer, pode-se considerar que a afirmativa de que atualmente seria impossível a coexistência da tecnologia médica avançada com a "naturalidade" ou "humanização" do morrer pode ser compreendida tanto como uma suposição quanto uma conclusão normativa. A implantação e expansão dos cuidados paliativos foi possível graças ao desenvolvimento de pesquisas médicas farmacológicas voltadas ao alívio de dor dos doentes terminais ${ }^{8}$.

Atualmente existem múltiplos discursos na literatura contemporânea sobre o que seria uma trajetória ideal do morrer - seja na divulgação do ideário, seja na produção analítica e crítica. Esses discursos são construídos 
histórica e culturalmente, e é através da compreensão de seus significados que se torna possível o acesso às demandas sociais relativas à vida, morte, saúde, doença e assistência médica (Seymour, 1999, p. 692). A intervenção médica e tecnológica durante o processo do morrer, na retórica dos militantes da causa da "morte natural", tornou-se emblemática da morte desumana e "não-natural".

O modelo da morte ideal, "natural", com autonomia e dignidade, é construído em contraposição ao modelo anterior, da morte tecnológica e desumana. O ideário da "boa morte" veicula como certa e definitiva a congruência de morte tecnológica e desumanidade, em franca oposição à morte "natural" - tornada equivalente ao termo humanização (Seymour, 1999, p. 692). Essa polarização acarreta uma reificação da "morte natural". $\mathrm{Na}$ literatura em prol da "boa morte natural", as clínicas altamente tecnológicas, nas quais a intervenção médica no processo do morrer é claramente visível, são descritas como exemplos extremos da metamorfose da morte - de um evento natural em um não-natural (Seymour, 1999, p. 692). A produção crítica considera que um medo está particularmente presente nos serviços altamente tecnologizados, como os Centros de Tratamento Intensivo: de que a equipe médica minimize os aspectos relativos ao sofrimento humano e à dignidade e lide com o morrer priorizando a luta pela manutenção das funções vitais (Seymour, 1999, p. 692).

A pesquisadora Jane Seymour, visando a examinar a reificação da "morte natural" e enfocando a polarização entre morte tecnológica e "natural", realizou ampla pesquisa etnográfica em dois Centros de Tratamento Intensivo para adultos, na Inglaterra. Seu estudo examina a validade dessa reificação, ao investigar casos relacionados às experiências de pessoas próximas a doentes que estiveram internados em CTIs. A escolha da pesquisadora, pela observação em CTI, deveu-se ao fato de se tratar de ambiente que conta com aparelhagem sofisticada, local exemplar da expressão contemporânea da medicina tecnológica, no qual o controle da morte e o prolongamento da vida se tornaram possíveis. As mortes ocorridas nesse setor hospitalar seriam exemplo paradigmático de um evento medicalizado, "nãonatural", nas quais quaisquer narrativas de "morte natural" estariam excluídas. Nesse ambiente não há, via de regra, trabalho visando a uma consciência da iminência da morte, ou voltado ao desenvolvimento pessoal através do processo do morrer, por meio de preparação social e psicológica para a morte.

No CTI, a certeza da relação linear entre o processo do morrer e a morte 
é constantemente desafiada pela aplicação de tecnologias - seja para salvar a vida, seja para retardar a morte. Quando ocorre a morte no CTI, esta em geral é caracterizada pela extrema vulnerabilidade e dependência corporal do moribundo, muitas vezes em virtude de um estado de inconsciência, causado pela severidade do estado biológico e/ou pela indução de um estado artificial pelo uso de drogas sedativas e analgésicas. Drogas são administradas para aliviar a dor inevitável e o desconforto causado pela doença e pelo uso de tecnologias invasivas para o tratamento. O exercício da escolha, controle e autodeterminação do moribundo - tão central na ideologia da "boa morte natural" - torna-se impossível.

Contudo, estudos desenvolvidos recentemente em ambientes de alta tecnologia médica apontam que, paradoxalmente, a mesma tecnologia médica avançada tornou-se parte relevante na construção da trajetória do "morrer natural". Essas pesquisas apontam que é exatamente a tecnologia que garante os meios de construção da "boa morte", modificando a trajetória do morrer em conseqüência de doença crítica, tornando esse processo aceitável para os atores sociais envolvidos (Seymour, 1999, p. 694).

$\mathrm{O}$ estudo de Seymour examina as estratégias empregadas pela equipe médica de CTI visando a uma "morte digna", através de complementação da etnografia com entrevistas realizadas com companheiros de pacientes de CTI, algum tempo após a observação etnográfica. Segundo a pesquisadora, as entrevistas forneceram oportunidade para incorporar as visões dos participantes da investigação desde o início da observação, possibilitando o esclarecimento de temas que emergiram durante a observação. Para a autora, tanto os relatos verdadeiros quanto os falsos sobre a realidade - comparados aos relatos médicos - são relevantes, uma vez que considera que eles representam as construções das perspectivas dos informantes.

Durante a análise e comparação dos dados, Seymour construiu um modo de classificação, identificando três padrões de expectativa e de resultado. Em cada um dos casos o familiar mais próximo foi entrevistado algum tempo após a internação, quando relatou suas expectativas e sentimentos durante a doença de seu parente.

A primeira categoria consiste em quando havia expectativa de morte e ocorreu uma recuperação do paciente. Esta categoria é exemplificada pelo caso de um homem de 55 anos, com septicemia. O doente tinha uma longa história de doença mental e de doença crônica física. Sua esposa percebeu a inesperada recuperação do marido como uma falha da tecnologia, pois considerou que a recuperação teria ocorrido por intervenção no curso natu- 
ral do morrer: seu marido teria sido salvo em conseqüência da aplicação da ciência médica, o que foi interpretado pela entrevistada como uma estranha alteração do curso natural da doença crônica do marido. A tecnologia foi compreendida como algo misterioso, imprevisível e miraculoso: sua utilização acarretou uma subversão ao processo natural dos eventos. O mesmo foi observado nos casos de outros entrevistados, mesmo quando a recuperação trouxe alívio e alegria para os parentes (Seymour, 1999, p. 695).

Na segunda categoria, na qual a morte era esperada e realmente ocorreu, a tecnologia teria desempenhado importante papel na busca da realização de uma seqüência "ideal" dos eventos. Cita, como exemplo, uma senhora de 73 anos, com problemas cardiovasculares. Neste caso, a equipe realizou um controle das medicações de modo que tudo ocorresse tranqüila e lentamente: assim, uma das filhas dessa senhora pôde chegar na cidade a tempo de se despedir da mãe. A morte ocorreu somente quando se tornou claro para todos que as opções de tratamento foram esgotadas e que seria inevitável o desfecho. A habilidade técnica da equipe médica em ajustar o tempo da morte e o fato de que ela tenha ocorrido em ambiente onde havia controle profissional foram fundamentais à idéia de uma morte tranqüila (Seymour, 1999, p. 697). Essa morte ocorreu em tempo "apropriado", "natural", no qual houve a confirmação do morrer técnico anteriormente à ocorrência da morte corporal. Tanto os profissionais como parentes e amigos do moribundo tiveram condições de aceitar e acompanhar a morte.

A terceira categoria, em que não havia expectativa de morte e esta ocorreu inesperadamente, é ilustrada por uma senhora de 71 anos, internada para uma cirurgia eletiva. Pouco após a cirurgia, a paciente apresentou sinais de desidratação e septicemia, sendo transferida para o CTI. Seis dias após a internação no CTI a doente sofreu uma piora, que culminou com uma parada cárdio-respiratória. Após tentativas de ressuscitação, foi declarado o óbito. Segundo Seymour, essa morte foi interpretada pelos familiares como "não-natural", uma interrupção do processo natural dos eventos. Teria ocorrido por falha da tecnologia, conseqüência das insuficiências no sistema de saúde. Os entrevistados disseram que sua fé na tecnologia foi traída pela falha médica - aí incluída a tecnologia médica (Seymour, 1999, p. 699).

De acordo com a pesquisadora, os casos estudados apontam que as percepções dos atores sociais sobre os significados da tecnologia dependem das circunstâncias particulares nas quais o morrer é administrado e das formas de utilização da tecnologia pela equipe de saúde. Em sua investigação, Seymour conclui que a "morte natural" teria sido preservada, segundo 
familiares dos doentes, quando a tecnologia médica permitiu uma evolução de acordo com o esperado, parecendo ser manipulável de forma humana. Deste modo, a tecnologia médica tornou-se compreensível e aceitável ao entendimento leigo (Seymour, 1999, p. 700). A representação da "morte natural" é construída em conexão com o controle médico da situação, o que depende intrinsecamente da tecnologia.

\section{Morte e Construção de Pessoa}

O modelo da "morte contemporânea", regido pelo ideal da "boa morte" - e, inserido nesse modelo, o da "morte natural" -, foi construído no final do século XX, na Inglaterra e nos Estados Unidos. Na radicalização da cultura do individualismo, que valoriza a vida única e singularmente vivida, a morte ideal é a "escolhida e produzida" pelo indivíduo que está a morrer - de modo semelhante ao que é veiculado pelo modelo do "parto natural". Assim, a forma como as pessoas nascem é considerada decisiva para a trajetória de suas vidas (Tornquist, 2002, p. 3). Tanto no "parto natural" como na "morte natural", os direitos individuais de autodeterminação convergiram com a proposta de que os profissionais lidem com o nascimento e com a morte de forma diversa da anterior, dando preeminência aos cuidados e à compaixão sobre a técnica ${ }^{9}$. O modelo contemporâneo do morrer está referido a uma construção de pessoa autônoma, singularizada, com direito ao conhecimento do diagnóstico e das opções terapêuticas. Trata-se de uma construção bastante distinta do modelo anterior de morte, quando o doente desconhecia a verdade acerca de sua patologia e não havia espaço para sua participação nas decisões terapêuticas. Contudo, na implantação do novo modelo de assistência ao doente terminal, surgem algumas dificuldades, uma das quais pode ser ilustrada por uma fala por nós coletada:

"Sabe, aí o médico me explicou a minha doença, e apresentou as opções: foi falando do arsenal terapêutico, uma série de detalhes que eu não entendia nada, radioterapia, radioterapia focal, cortisona, quimioterapia, fisioterapia, morfina (...) dizendo os efeitos colaterais e o que ia melhorar, e no final me perguntou: então, o que você escolhe? E eu tinha lá condições de escolher alguma coisa? Aquilo tudo me confundiu (...) Eu só queria ter menos dor (...)" (mulher de 50 anos).

Não há dúvidas de que esse médico seguiu o manual do modelo da "morte contemporânea", expressando a vertente dos cuidados paliativos, que 
considera que o imperativo é prosseguir tratando e atuando ativamente através da maior utilização dos recursos terapêuticos. Já para outros profissionais, a meta na assistência paliativa é o alívio da dor e do desconforto. Há, em geral, uma visão preeminente de que os sintomas do morrer devem ser tratados a todo custo - mesmo na prática dos cuidados paliativos, que postulam que a morte é uma parte natural da vida e que deve ser aceita no devido momento. De qualquer modo, pode-se afirmar que os modelos da "boa morte" e da "morte natural" são compreendidos diversamente, de acordo com os contextos sociais em que são implantados. Do mesmo modo, os programas de assistência em cuidados paliativos implementados em distintos países e regiões dirigem-se a extratos sociais os mais variados, com construções de pessoa diversas.

A partir de nossa pesquisa etnográfica, tomamos conhecimento de que, na assistência pública paliativa inglesa, os profissionais não costumam realizar medida da pressão arterial de seus pacientes - por considerarem tal procedimento desnecessário. Já no Brasil, a mensuração da pressão arterial faz parte de qualquer atendimento médico, inclusive o paliativo, uma vez que a medida da pressão arterial já foi incorporada culturalmente como dado fundamental acerca de uma boa saúde e sobre uma boa assistência em saúde. Da mesma forma, os recursos técnicos e tecnológicos podem ser classificados diversamente segundo os contextos e as relações entre os atores sociais envolvidos - como demonstra a pesquisa de Seymour. Assim, é na prática do trabalho clínico e da negociação entre os envolvidos que o impacto da aplicação da tecnologia se dá.

\section{Considerações Finais}

As imagens contemporâneas ideais da morte (e do nascimento) encontram-se intimamente articuladas a uma construção de naturalidade desses processos. Entretanto, atualmente existe uma confiança fundamental nas intervenções tecnológicas "leves" durante o parto e no processo do morrer visando ao alívio da dor, desde que sem sedação profunda.

Esse dado aponta uma percepção da tecnologia como menos determinante de uma morte desumana e não-natural do que a posição antitecnológica reivindica. Tanto no nascimento como na morte, o indivíduo pode escolher e combinar elementos de suas preferências, a partir de um espectro de fontes potencialmente contraditórias, como, por exemplo, cromoterapia e quimioterapia (Seymour, 1999, p. 693). 
O ideário contemporâneo da "boa morte" veicula a idéia de que a principal autoridade a tomar decisões acerca da vida, sofrimento e morte seria o próprio doente. Não há dúvidas de que se trata de uma proposta igualitária na relação entre os atores sociais envolvidos com a situação de doença. Contudo, um paradoxo se apresenta: a própria tecnologia engendra as condições de desenvolvimento de uma medicina desumana e tecnológica, assim como também é propiciadora de propostas naturais e de humanização - com as tecnologias "leves". Surgem questões sobre o emprego da tecnologia, acerca da autonomia do doente diante dos recursos terapêuticos, especialmente ao se tratar de doença terminal - o que, via de regra, é condição que causa extrema ansiedade.

Essas novas construções de morte (como também de nascimento) refletem e implicam reconfigurações da pessoa, variáveis segundo os referenciais hegemônicos negociados de cada cultura. Uma vez que, em nossa cultura ocidental contemporânea, percebemos, pensamos, falamos e agimos sobre nossos corpos e suas falhas referenciados ao discurso médico, é possível especularmos sobre novas construções de pessoa nos modelos da "morte contemporânea" e no modelo da "morte natural". É possível afirmar que tais modelos, surgidos em contraposição ao modelo anterior da "morte moderna", tecnologizada e desumana, buscam resgatar uma totalidade perdida do doente.

Os modelos recentes de morte podem ser compreendidos, ao menos em parte, como um resgate de valores que teriam sido abolidos ou ocultados, como a condição de indivíduo autônomo e independente do doente terminal. O paciente, anteriormente silenciado e objetificado pelo poder do profissional exercendo uma prática medicina racionalizada, passa a ser visto e percebido pela equipe de cuidados paliativos como "um todo biopsicossocial-espiritual". O modelo contemporâneo de morte propõe uma assistência que alcance essa multiplicidade de aspectos, chegando à imersão em uma totalidade.

Uma de nossas hipóteses seria a de que essa construção recente corresponderia a uma tentativa de resolução da inarredável tensão estruturante de nossa sociedade ocidental contemporânea, entre Romantismo e Racionalismo, em especial de sua expressão e manifestação no campo da medicina ${ }^{10}$. Vivemos atualmente num mundo fragmentado, no qual tanto a identidade individual como seu referente corporal muitas vezes são percebidos e vividos de modo fracionado. As propostas recentes de construção de modelos de morte e do morrer podem então ser compreendidas como tentativas de acesso a uma totalidade perdida, em um resgate neo-romântico, 
como resposta à fragmentação do mundo e do corpo. Indo além, aventa-se aqui a hipótese de uma ressacralização do mundo, da vida, do corpo e da pessoa através desse novo processo de morte.

A medicina e seus recursos tornaram-se, atualmente, tanto fonte da esperança - através da criação da vida, de seu prolongamento, do retardamento da morte, de alívio do sofrimento - quanto do desespero diante dos limites da condição humana. $\mathrm{O}$ debate permanece em aberto, uma vez que a condição humana implica necessariamente sua finitude - apesar de todos os esforços da ciência e da tecnologia médica voltados a transformar e ultrapassar os limites dessa condição.

\section{Referências Bibliográficas}

ALBERY, N.; WIENRICH, S. (Ed.). The new natural death: handbook. 3 ed. London: Rider, 2000. 382p.

AMARANTE, P. (Org.). Loucos pela vida: a trajetória da Reforma Psiquiátrica no Brasil. 2. ed. Rio de Janeiro: Fiocruz, 1998. 132p.

ARIÈS, P. Essais sur l'histoire de la mort en Occident, du Moyen Age à nos jours. Paris: Seuil, 1975. 223p.

. O homem perante a morte. II. Lisboa: Publicações EuropaAmérica, 1977. 373p.

BONET, O. Saber e sentir: uma etnografia da aprendizagem em Biomedicina. 153 f. Dissertação (Mestrado em Antropologia Social) - Museu Nacional, Universidade Federal do Rio de Janeiro, 1996.

CAMARGO JR., K. R. (Ir)racionalidade médica: os paradoxos da clínica. PHYSIS - Revista de Saúde Coletiva. Rio de Janeiro, v.2, n. 1, p. 203-227, 1992.

CLARK, D.; SEYMOUR, J. Reflections on Palliative Care. Buckingham: Open University Press, 1999. 213p.

CORREAA, M. Novas tecnologias reprodutivas: limites da biologia ou biologia sem limites? Rio de Janeiro: Ed. UERJ, 2001. 263p.

DUARTE, L. F. D.; LEAL, O. F. (Org.). Doença, sofrimento, perturbação: perspectivas etnográficas. Rio de Janeiro: Fiocruz, 1998. 210p. 
ELIAS, N. A solidão dos moribundos. Rio de Janeiro: Jorge Zahar, 2001. $107 \mathrm{p}$.

FERREIRA, G.; FONSECA, P. (Org.). Conversando em casa. Rio de Janeiro: Sette Letras, 2000. 141p.

FOUCAULT, M. O nascimento do hospital. In: Microfisica do poder. 14. ed. Rio de Janeiro: Graal, 1999. 295p.

GLASER, B.; STRAUSS, A. Awareness of dying. Chicago: Aldine, 1965. Time for dying. Chicago: Aldine, 1967.

GOOD, B. J.; GOOD, M.-J. Learning medicine: the construction of medical knowledge at Harvard Medical School. In: LINDEBAUM, S.; COCH, M. (Ed.). Knowledge, power and practice: the Anthropology of Medicine and everyday life. California: University of California Press, 1993.

HARARI, A.; VALENTINI, W. (Org.). A Reforma Psiquiátrica no cotidiano. São Paulo: Hucitec, 2001. 141p.

HERZLICH, C. Os encargos da morte. Rio de Janeiro: UERJ, IMS, 1993. 40p. (Série Estudos em Saúde Coletiva, 52).

KÜBLER-ROSS, E. On death and dying. New York: MacMillan, 1969. 289 p.

LE BRETON, D. A síndrome de Frankenstein. In: SANT’ANNA, D. B. (Org.). Políticas do corpo. São Paulo: Estação Liberdade, 1995.

LOCK, M. On dying twice: culture, technology and the determination of death. In: LOCK, M.; YOUNG, A.; CAMBROSIO, A. (Org.). Living and working with the new medical technologies, intersections of inquiry. Cambridge: Cambridge University Press, 2000.

MCNAMARA, B. A good enough death? In: PETERSEN, A.; WADDELL, C. Health matters. A sociology of illness, prevention and care. 2 ed. Buckingham: Open University Press, 1999. 370p.

MENEZES, R. A. Difíceis decisões: uma abordagem antropológica da prática médica em CTI. 98 f. Dissertação (Mestrado em Saúde Coletiva) - Instituto de Medicina Social, Universidade do Estado do Rio de Janeiro, 2000.

PESSINI, L. Distanásia. Até quando prolongar a vida? São Paulo: Centro Universitário São Camilo, 2001. 427p.

SALEM, T. Sobre o casal grávido: incursão em um universo ético. Tese (Doutorado em Antropologia Social) - Programa de Pós-graduação em Antropologia Social / Museu Nacional, Universidade Federal do Rio de Janeiro, 1987.

SEYMOUR, J. E. Revisiting medicalisation and 'natural' death. Social Science \& Medicine, v. 49, p. 691-704, 1999. 
Critical moments. Death and dying in Intensive Care. Buckingham: Open University Press, 2001. 185p.

SOUZA, A. N. Formação médica, racionalidade e experiência: o discurso médico e o ensino da clínica. Tese (Doutorado) - IPUB, Universidade Federal do Rio de Janeiro, 1998.

SUDNOW, D. Passing on: the social organization of dying. New Jersey: Prentice-Hall, 1967. 176p.

TORNQUIST, C. S. Pessoa e sexualidade no ideário do movimento pela humanização do parto e do nascimento. Reunião da ABA, 23. Anais... Gramado, 2002. Mimeografado.

VELHO, G. Nobres e anjos: um estudo de tóxicos e hierarquia. Rio de Janeiro: Fundação Getúlio Vargas, 1998. 214p.

WALTER, T. The eclipse of eternity. A sociology of afterlife. London: MacMillan, 1996. 222p. . The revival of death. 2 ed. London: Routledge, 1997. 228p.

\section{NOTAS}

1 Médica, mestre e doutoranda em Saúde Coletiva, Instituto de Medicina Social da UERJ.

2 Ariès cunhou os termos "morte tradicional" e "morte moderna" em seus estudos históricos sobre a morte $(1975 ; 1977)$. A oposição "tradicional/moderno" é tomada como instrumento preliminar de análise. Os modelos de "morte tradicional" e "moderna" são tratados por diversos autores como tipos ideais no sentido weberiano e utilizamos essas mesmas denominações. A "morte tradicional" foi investigada do ponto de vista histórico por Ariès (1975, 1977), que considera que o morrer na sociedade tradicional era vivenciado de modo mais familiar e onipresente: a morte era um acontecimento social, vivida na e pela comunidade, menos privatizada do que no século XX. A "morte moderna", instaurada ao longo do século $\mathrm{XX}$, foi investigada por diversos autores, dentro os quais Elias, que considera que o processo de ocultamento da morte faria parte do impulso civilizador iniciado na Europa há cerca de quinhentos anos (Elias, 2001, p. 18). Além da pesquisa de Elias, destacamos três estudos pioneiros no campo das ciências sociais, sobre o modelo da "morte moderna", de Sudnow (1967) e Glaser e Strauss (1965; 1967). A psiquiatra Elizabeth Kubler-Ross também desenvolveu pesquisa influente sobre o mesmo tema, enfocando especificamente o estado emocional dos doentes (Kubler-Ross, 1969).

3 Optamos por utilizar a nomenclatura “contemporânea" por considerá-la mais neutra, uma vez 
que as outras duas são indicativas de um certo comprometimento ideológico. Atualmente há uma produção analítica e reflexiva sobre esse modelo de morte, e citamos, em especial, Clark \& Seymour (1999); Lock (2000); McNamara (1999); Seymour (1999; 2001); Walter (1996; 1997) e Pessini (2001). O modelo da "morte contemporânea" compreende o movimento pelos hospices, também denominado movimento pelos cuidados paliativos (sejam estes prestados em enfermarias hospitalares, em instituições específicas ou na própria residência do doente). Os hospices são instituições criadas e desenvolvidas com o intuito de proporcionar conforto e amparo aos moribundos. O primeiro hospice foi fundado em Londres por Cicely Saunders, em 1967 (St. Christopher Hospice), e tornou-se exemplar do novo modelo de assistência. Utilizamos também as expressões "morrer bem" ou o modelo da "boa morte" como referentes ao modelo de "morte contemporânea", pois sua meta é proporcionar uma "boa morte" aos doentes terminais atendidos por equipe de cuidados paliativos.

$4 \mathrm{O}$ modelo foi rapidamente incorporado pelo aparato médico. O primeiro hospice norteamericano foi fundado em 1974. Atualmente os cuidados paliativos são reconhecidos como especialidade e há uma associação americana de CP, a American National Hospice Organization, criada em 1978 (Pessini, 2001, p. 207). Na Inglaterra o movimento pelo hospice foi uma resposta inovadora em contraposição à negligência dos profissionais em relação ao alívio da dor da maior parte dos pacientes terminais com câncer. $\mathrm{O}$ processo nos Estados Unidos tomou um caminho diverso, refletindo a preocupação cultural com o individualismo daquele país, no qual a preparação psicológica para a morte é fundamental, sendo percebida como a etapa final no desenvolvimento pessoal. A proposta dos cuidados paliativos surgiu no Brasil algumas décadas após, e a primeira unidade pública de assistência paliativa brasileira foi implantada no Rio de Janeiro, em 1986.

5 De modo semelhante ao que ocorreu durante a Reforma Psiquiátrica, com o processo de desinstitucionalização dos doentes mentais e a passagem da delegação social dos encargos dos doentes à família. A este respeito, ver Ferreira \& Fonseca (2000); Amarante (1998); Harari \& Valentini (2001), entre outros.

6 Segundo Salem (1987), as propostas de ruptura em relação ao movimento biomédico hegemônico em relação ao parto remontam aos anos 1950, com o "parto sem dor". Esse movimento foi reapropriado nos anos 1970/80 pelos movimentos contraculturais, com o ideário do "parto natural". Como desdobramento desses movimentos surge, ao longo dos anos 1990, o movimento pela humanização do parto e nascimento. Sobre o tema, ver Salem (1987) e Tornquist (2002).

7 A geração da vanguarda dos anos 1960 fundou o movimento hippie, buscou a expansão da consciência através do uso de drogas alucinógenas e, com o advento da pílula anticoncepcional, promoveu mudanças nas relações sexuais, com o chamado "amor livre" e nas relações de gênero. Foi também a geração a desenvolver movimentos pacifistas, pela liberdade de expressão, e os movimentos estudantis de 1968. Segundo Albery et al., quando os integrantes dessa geração optaram por ter filhos, escolheram e divulgaram a prática do parto natural e da amamentação. Mais adiante criou o movimento ecológico, no qual se insere o movimento pela "morte natural", condizente com os ideais vividos anteriormente (Albery, 2000, p. 6). Timothy Leary foi um exemplo dessa geração, na Califórnia (Estados Unidos): líder de movimentos pacifistas americanos, foi professor universitário, defendeu o uso de drogas alucinógenas (como o LSD) e realizou pesquisas sobre a expansão de consciência através da utilização dessas drogas. Por seu desejo, sua morte foi transmitida - via Internet - para todo o mundo e sua cabeça está sendo mantida em laboratório de criogenia. Para Velho (1998), a principal característica dessa geração seria a busca constante de mudança e transformação.

8 Pioneira no movimento pelos hospices, Cicely Saunders, voltou-se especialmente à pesquisa 
de medicações para alívio da dor dos doentes terminais. Pode-se afirmar que o mesmo movimento ocorreu na Reforma Psiquiátrica, quando foi possível a desinstitucionalização dos doentes mentais, também em decorrência do advento dos novos medicamentos antipsicóticos.

9 Pode-se discutir a aplicação, na prática, da proposta de autonomia do doente, tendo em vista os distintos contextos socioculturais. Em uma pesquisa etnográfica em hospices australianos, a autora considera que um médico morrendo de câncer teria melhores condições de negociar com a equipe sobre a administração de medicamentos do que um aborígene (McNamara, 1999, p. 178). Na medida em que os profissionais de saúde estejam remetidos a um modelo ideal - de parto e de morte - pode haver uma indução dos pacientes a realizarem esse modelo. Como exemplo, a fala de uma profissional de saúde sobre um parto, a partir de etnografia de uma maternidade pública brasileira regida pelo modelo da humanização do parto e do nascimento: "nunca vi uma mãe tão frouxa..."; ou a fala de uma parturiente: "depois de tudo o que passei, achando que ia parir de cócoras, ser levada para uma cesárea, ser cortada (...) Não tinha leite, não tinha nada, e aquelas enfermeiras passando toda hora para saber se tem leite (...). Isto é chamado humanização?" (Tornquist, 2002, p. 10). O mesmo pode ser dito com relação ao processo de morrer. Citamos a fala de um profissional de uma unidade pública brasileira de cuidados paliativos coletada em pesquisa etnográfica: "a gente quer fazer cuidados paliativos tudo direitinho, seguir o modelo (...). Mas esta gente nasce que nem bicho, vive que nem bicho, e a gente querendo que possam morrer bem (...) não dá, eles não entendem (...)" (médico).

10 Sobre a inarredável tensão, ver Duarte (1998, p. 15). Segundo diversos autores (Camargo, 1992, p. 204; Good \& Good, 1993, p. 91; Bonet, 1996; Souza, 1998; Menezes, 2000), a medicina é constituída por uma dupla dimensão estruturante, cujos pólos ("tecnologia/ humanismo") estariam em constante tensão. 


\section{ABSTRACT}

Technology and "Natural Death": Dying in Contemporary Society

The development of techniques to prolong life has brought significant changes in the conceptualization of death. This article analyzes contemporary representations of "natural death" and their relationship to the use of medical technologies. Based on a literature review, the article examines the concepts of "natural death" and "dying well" constructed by the various social actors involved in the process of dying. The literature reveals the contemporary construction of a necessary set of ideals and pathway for achieving the model of a "good death". The "dying well" model is constructed in opposition to techniques for prolonging life. The studies point to the complexity and ambivalence of what is presented as "natural" versus "unnatural" death, since such representations are intertwined with the concept of a "good death" as that which is "chosen and produced" by the patient. Thus, medical technology becomes intrinsically constitutive for a "natural death".

Key words: Death, medical technology, natural death, palliative care.

Recebido em: 14/05/2003.

Aprovado em: 07/08/2003. 